\title{
ADVANCE Mentoring Programs for Women Faculty in SEM at the University of Washington
}

\author{
Joyce W. Yen ${ }^{1}$, Kate Quinn ${ }^{1}$, Sheila Edwards Lange ${ }^{2}$, Eve A. Riskin ${ }^{1}$, and \\ Denice D. Denton ${ }^{1}$ \\ ${ }^{1}$ University of Washington ADVANCE Center for Institutional Change / \\ ${ }^{2}$ University of Washington Center for Workforce Development
}

\begin{abstract}
The mentoring literature has shown that faculty can benefit from multiple mentors and networking opportunities. As a result, the University of Washington's ADVANCE Center for Institutional Change has designed a series of group mentoring programs for women faculty in science, engineering, and mathematics. This paper discusses these mentoring programs and provides guidelines for replication at other institutions.
\end{abstract}

\section{Introduction}

A recent article in the Chronicle of Higher Education posed the question "Where are all the Women"? ${ }^{1}$ Indeed, although female U.S. citizens are now earning more Ph.D.'s than male U.S. citizens across all disciplines, ${ }^{2}$ faculty continue to be largely male dominated. ${ }^{3}$ An even more unbalanced picture exists in science, engineering, and mathematics (SEM). In 2003, women earned $43 \%$ of the SEM Ph.D.'s awarded to U.S. citizens. ${ }^{2}$ However, at the top 50 SEM departments, as determined by research dollars, only $8.4 \%$ of the faculty in 2002 were women. ${ }^{4}$ Furthermore, the representation of women among SEM Ph.D. recipients is not equally reflected among assistant professors. ${ }^{4}$

Clearly women in SEM are operating in male-dominated fields. As such, they often encounter subtle (sometimes overt) biases which can impact their ability to achieve their full potential, to have access to information and build social capital, and to be viewed as leaders. Indeed, similar to Valian' $s^{5}$ discussion of gender schemas and the 'accumulation of disadvantage', Sonnert's study Project Access ${ }^{6}$ and Mary Frank Fox's ${ }^{7}$ research on productivity have confirmed subtle barriers that, compounded over time, result in major disparities in the career advancement of women and men in academia nationally. Their research indicates that:

- Among younger women in the physical sciences, mathematics, and engineering, the average academic status was almost one full rank below a comparable cohort of men.

- Women experience subtle but noticeable marginalization in the social system of science (e.g., left out of decisions and social gatherings). 
- Women of equal stature to men have a slightly lower estimation of selfconfidence, ambition, and related traits.

- Family issues (e.g., dual-career couples and tenure vs. the biological clock) tend to impact careers of women more then men.

Thus, small incremental obstacles that slow down the careers of women tend to be much more prominent than clear-cut barriers. These obstacles are both structural and psychological.

Once women join the SEM faculty, understanding exactly what is required to advance can often be problematic. Strategies must be developed to support the experience of the women faculty so they can advance science and engineering with their innovations, creativity, and diverse points of view and serve as role models to future faculty.

One successful strategy is mentoring. The findings of a study of 430 faculty supported the benefits of mentoring. ${ }^{8}$ Others also address the positive influences of senior colleagues mentoring junior faculty. ${ }^{9}$ Moreover, two of Creamer's four elements in the environment that may assist women to become highly productive scholars are: (1) opportunities for development of skills required for competence in scholarly research, writing, and publication and (2) a network of collegial relationships within and outside the institution, often through professional associations. $^{10}$

This paper describes several mentoring programs for women faculty in SEM at the University of Washington. The program goals are to help junior women SEM faculty advance to senior positions and to model a pathway for senior women SEM faculty to advance into leadership positions.

The paper begins with a discussion of the literature on mentoring faculty. Next the University of Washington ADVANCE Center for Institutional Change, the organization that created and manages the mentoring programs, is described, followed by a detailed description of each mentoring activity. The paper concludes with recommendations for replication.

\section{Literature on Mentoring Female Faculty}

The concept of mentoring has various definitions. The most common is that of a relationship between an experienced, successful individual and a less experienced 'protégé' whereby the latter receives guidance and advice from the former. ${ }^{11-25}$ Mentoring is "a process by which you are guided, taught, and influenced in your life's work in important ways" and a mentor is "a person who leads, guides, and advises a person more junior in experience" (p. 42). ${ }^{20}$ The 'symbiotic partnership' of a mentoring relationship is "widely regarded as an important aspect of the training and career development of young professionals" (p. 315), ${ }^{18}$ and benefits of mentoring received by protégés include "[enhancing] an individual's chances of being successful" (p. 16), "career mobility, early career success, work and career satisfaction, and career advancement (p. 615)," ${ }^{, 24}$ and "lower turnover intentions and less work-non-work conflict (p. 264)." ${ }^{25}$ Ideally, good mentoring creates an environment where "giving and receiving guidance are embedded in the values and norms of the organization (p. 180)."16 
Mentoring can be an important part of a faculty member's professional development. As Boice notes, "Success or failure in professorial careers begins with social supports (p. 19)."

Successful mentoring helps create "a satisfactory working environment and ... a feeling that a particular department is one in which a young faculty member can continue to grow, create and expand knowledge, and make contributions that will be rewarded (p. 14)." 27 It is a mechanism by which faculty obtain career guidance, information on department culture, insights on how to navigate the academic system, access to professional networks, etc. Mentoring is especially beneficial to minority faculty members, who, unfortunately, are "least likely to find substantial mentoring" (p. 34) ) $^{26}$ and to women in general, who are "less likely than men to have been assigned an official mentor (p. 273)." 26 As noted by Tierney \& Bensimon, "women's academic groups are also responsible for much of the formal and informal mentoring that women receive (p. 100)."28

An observation should be made when mentoring faculty. Due to the 'peer' relationship between faculty members within a department, it is possible that the mentor relationship is different between faculty members from that which exists between a subordinate and a supervisor. ${ }^{16}$ For example, Sands et al. note that the potential of having the mentor involved in the protégé's evaluation for tenure or promotion creates an "unequal and vulnerable position" for the protégé (p. 174). ${ }^{16}$ Therefore it is critical that faculty have multiple sources for mentoring guidance and that these potential conflicts of interest be carefully monitored.

Indeed, research suggests that multiple mentors may better serve the needs of protégés through the multiple viewpoints and skills brought to the relationship. ${ }^{25}$ Baugh \& Scandura note, "A protégé may learn more strategies for approaching tasks, particularly onerous one, from multiple mentors, and thus job satisfaction may increase as the number of mentoring relationships increases (pp. 505-506)." 11 Additionally, informal group mentoring activities expose mentees to a variety of mentors who can provide different methods for success in aspects of academic life, increasing the network of potential supports for each mentee without creating additional time demands on either the mentor or the mentee. ${ }^{25}$ Granovetter found "weak ties," or connections that are not considered strong or intimate, to be "indispensable to individuals" opportunities and to their integration into communities." 29 Basically, "more information vital to scholarly productivity will come from interacting with a large set of people than with a smaller number." 18

\section{University of Washington ADVANCE}

As previously mentioned, the goals of the UW ADVANCE mentoring programs are to help junior women SEM faculty advance to senior positions and to model a pathway for senior women SEM faculty to advance into leadership positions. These mentoring programs were created under a National Science Foundation ADVANCE Institutional Transformation grant.

The University of Washington was one of the initial eight universities selected for a National Science Foundation ADVANCE grant in the fall of 2001. The UW has a Carnegie ranking of Doctoral/Research University/Extensive and for the past thirty years it has been the number one public university in the country in receiving federal support for research and training. Its female science and engineering faculty members are recipients of numerous national awards including National Science Foundation Young Investigator CAREER Awards and Sloan Research 
Fellowships. The UW ADVANCE project was designed to build upon existing strengths at the university while serving as the catalyst for institutional transformation. The project's vision as articulated in the original proposal is "a campus in which all SEM departments are thriving, all faculty are properly mentored, and every SEM faculty member is achieving to his or her maximum potential.”

The UW ADVANCE program created a Center for Institutional Change (CIC) that is advised by a joint leadership team from the College of Engineering and the College of Arts and Sciences. The leadership team includes deans, chairs and faculty members from both colleges, the associate dean of the graduate school, the vice president for minority affairs and the university's human resources vice president. Academic departments participating in the program include all ten within the College of Engineering and nine of the eleven in the College of Arts and Sciences' Division of Science.

Key programmatic areas include leadership development for chairs, deans, and emerging leaders; mentoring women faculty in SEM; policy transformation; departmental cultural change; a Transitional Support Program that makes small grants to outstanding faculty members; and a Visiting Scholars Program to bring scholars to the UW campus. This paper focuses on its mentoring programs for women faculty.

\section{Mentoring Women Faculty at UW}

Because multiple and group mentoring have proven to be successful in that mentees benefit from hearing multiple perspectives on career development, ${ }^{11,21,25}$ the UW ADVANCE program provides group mentoring to its women faculty. Its mentoring programs include a junior faculty mentoring program; Professional Development Consultants in each College who are available to discuss promotion and tenure concerns; a mentoring-for-leadership program; and the Transitional Support Program.

It should be noted that these programs were created in response to focus group feedback which was collected at the beginning of the ADVANCE grant. During these sessions, women faculty were asked about their mentoring preferences, topics of interest, and best ways to address their needs as women faculty. The programs have been very successful in part because these programs grew out of women faculty's suggestions.

\section{Junior Faculty Mentoring Program}

The junior faculty mentoring program emphasizes group mentoring rather than traditional oneon-one mentoring. Each quarter, different senior faculty members offer a workshop that covers "nuts and bolts" topics related to achieving tenure and having a successful faculty career. To date, 10 workshops and events have been offered. Most of the workshops occur over lunch, with the CIC providing lunch. Sample workshop topics include Navigating the Tenure Track, Working with College Development Offices, Time Management, Managing Research Groups, Mentoring and Advising Graduate Students, and Balancing Research and Teaching. Some of the workshops are offered to women only, while other workshops are open to all SEM assistant professors in ADVANCE departments. The workshops frequently highlight some of the 
common issues for women faculty and tips for avoiding these pitfalls. For example, the "Navigating the Tenure Track" covers first steps, issues for women and life balance.

Workshops are given by administrators and senior faculty and because the speakers rotate, the junior women are put in contact with a number of different women and men who can later serve as one-on-one mentors. Nineteen different speakers have presented at the workshops. Frequently a College of Engineering faculty member is paired with a College of Arts and Sciences faculty member to lead the workshop. This pairing allows participants to engage with faculty from different backgrounds and facilitates cross-college networking. Beyond these workshops, senior faculty are available to read and edit proposals, such as those for the NSF CAREER Award.

Many faculty have participated in these mentoring activities. Attendance at each workshop has ranged from seven to 17 participants. A total of 81 people, representing 17 of the 19 ADVANCE departments as well as several other departments on campus, have attended at least one of the ten workshops.

\section{Professional Development Consultants}

ADVANCE has secured Professional Development Consultants in each College to offer informal advice to women faculty about portfolio development, the promotion and tenure process, and professional development. Each Consultant is a former member of the College Promotion and Tenure committee, and hence has insight into the promotion process at the college level. The Professional Development Consultant in the College of Engineering is the former Chair of the College Promotion and Tenure committee. In addition to individual consultation, the Consultants have offered a workshop on the college-level tenure review process. Anecdotal evidence from junior women faculty has shown that this process has been effective in reducing anxiety about the promotion process, among other benefits. This program does not ensure promotion or career advancement but can help dispel some myths about the promotion and tenure process.

\section{Mentoring-for-Leadership Program}

For junior and senior women faculty, ADVANCE has implemented a leadership development program to encourage women faculty to consider and pursue positions of academic leadership. Women frequently pursue non-traditional career paths as compared with men, which is highlighted by the fact that of the first four women deans of engineering at research universities (Duke, Johns Hopkins, Michigan State, and UW), none has served as a department chair. This program, which was launched in May 2003, is intended to help women faculty realize the various paths to positions of leadership and to help inform them about academic organizational structures.

The ADVANCE Mentoring-for-Leadership lunch series is a monthly lunch gathering for SEM women faculty. Each month, a different woman leader such as a Dean, Divisional or Associate Dean, or Department Chair, from the University of Washington or another university, discusses her career trajectory and benefits and challenges of holding an administrative job. To date the program has featured five external speakers and eleven internal leaders. Emphasized are 
techniques for time management, balancing family and career demands, obtaining consensus among faculty, and implementing a vision of excellence. The seminars offer women faculty an opportunity to learn what it is like to be in a particular leadership position; to learn what strategies other women leaders use to navigate their various responsibilities; and to be encouraged to consider taking leadership positions. To date, 93 women have participated in the 16 lunch events and nearly 50 percent have attended multiple lunches. The participants represent all 19 ADVANCE departments as well as several other departments at UW.

Evaluation feedback showed that most women attendees appreciate hearing different perspectives on leadership and asking speakers questions about leadership. Several women have reported that the program is influencing how they view leadership and their suitability for taking on such roles. Moreover, this opportunity to gather over lunch creates networking and peer mentoring opportunities. Participants report feeling a greater sense of community among the women faculty in SEM due to these activities. Since the program's inception, one woman has taken a position as Divisional Dean and a second has become an Associate Chair.

\section{Transitional Support Program}

The ADVANCE Transitional Support Program (TSP) provides small grants to individual faculty members undergoing life transitions such as childbirth, eldercare, or major illness in a family member. The grants are awarded based on an application process in which the applicant describes the type of transition she/he is experiencing, how it has/will impact her or his career, and how the award would help advance her or his career. It is strongly encouraged that the a letter of support from the department chair be included in the application.

An unintentional consequence of the TSP has been the informal mentoring of some of the applicants, regardless of whether the proposal is selected for funding. When applications are not selected, a CIC staff member, whenever possible, introduces the faculty member to other campus resources and programs, and gives advice on how to write more competitive proposals in the future. In addition, involving the department chair in the situation, through requesting the letter of support, often provides additional mentoring to the faculty member by the department chair.

\section{Recommendations for Replication}

Beyond the specific ideas given in the previous section for implementing these program, some additional recommendations can be made. The mentoring programs described here are easy to implement and are generally very low cost (primarily catering and handouts). Because they are all group format, they also do not require large time commitment from faculty or program staff. The main challenge is to identify the topics and the appropriate speakers for each. Topics can be easily identified through focus groups and other feedback mechanisms such as workshop evaluations or web surveys. High visibility visitors to campus can make ideal workshop speakers. Because different faculty speak at each event, the workload is shared. The key ideas are providing opportunities for faculty to engage with other faculty, hear speakers address topics key to faculty success and leadership development, and develop networks. 
It is advisable to have formal ways to evaluate the programs. This evaluation enables the program staff to monitor outcomes and change programs as needed. It also allows for needs assessment or feedback from female faculty. It also helps to build in expectations that participants will be involved in evaluation and program feedback so as to ensure continuous program improvement.

\section{Summary}

This paper has described the ADVANCE CIC's series of mentoring programs for women faculty in SEM at the UW. Programs include the junior faculty workshops, professional development consultants, mentoring-for-leadership lunches, and the Transitional Support Program. The programs are low cost and easy to implement and enable large numbers of women faculty to be reached. Recommendations are given for replication at other institutions.

\section{Acknowledgements}

This work is made possible through a National Science Foundation grant (SBE-0123442). The authors are indebted to Mr. David Atsales, the CIC Program Operations Specialist, for handling the program logistics.

\section{References}

1. Wilson, R., Where the elite teach, it's still a man's world. Chronicle of Higher Education, 2004. 51(15): p. A8-A14.

2. National Science Foundation Division of Science Resource Statistics, Science and Engineering Doctorate Awards: 2003, NSF 05-300, Project Officer, Joan S. Burrelli: Arlington, VA 2004.

3. Mason, M.A. and M. Goulden, Marriage and Baby Blues: Redefining Gender Equity in the Academy. Annals of the AAPSS, 2004. 596: p. 86-103.

4. Nelson, D.J. and D. Rogers, A national analysis of diversity in science and engineering faculties at research universities. 2004, Norman, OK: [online] http://cheminfo.chem.ou.edu/ djn/diversity/briefings/Diversity\%20Report\%20Final.pdf.

5. Valian, V., Beyond Gender Schemas: Improving the Advancement of Women in Academia. NWSA Journal, 2004. 16(1): p. 207-220.

6. Sonnert, G., Gender Equity in Science: Still and Elusive Goal. Issues in Science and Technology, Winter 1995-1996: p. 53-58.

7. Fox, M.F., Women, Academia, and Careers in Science and Engineering, in The Equity Situation: Fostering the Advancement of Women in the Sciences, Mathematics, and Engineering., C. Davis, et al., Editors. 1996, Jossey-Bass Publishers: San Francisco.

8. Merriam, S.B., T.K. Thomas, and C.P. Zeph, Mentoring in higher education: what we know now. Review of Higher Education, 1987. 11(2): p. 199-210.

9. Jones, L.K., S.A. Hoenack, and M. Hammida, Career development of tenure-track assistant professors. Thought \& Action, 1994. 9(2): p. 147-172.

10. Creamer, E.G., The Scholarly Production of Women Academics. Initiatives, 1995. 57(1): p. 8.

11. Baugh, S.G. and T.A. Scandura, The effect of multiple mentors on protege attitudes toward the work setting. Journal of Social Behavior and Personality, 1999. 14(4): p. 503-521.

12. Burke, R.J., Mentors in organizations. Group and Organization Studies, 1984. 9: p. 353-372.

13. Fagenson, E.A., Perceptions of proteges' vs. nonproteges' relationships with their peers, superiors, and departments. Journal of Vocational Behavior, 1994. 45: p. 55-78.

14. Kram, K.E., Mentoring at Work. 1985, Glenview, IL: Scott, Foresman. 
15. Zey, M., The mentor connection. 1984, Homewood, IL: Dow Jones-Irwin.

16. Sands, R.G., L.A. Parson, and J. Duane, Faculty mentoring faculty in a public university. The Journal of Higher Education, 1991. 62(2): p. 174-193.

17. Moore, K.M. and A.M. Salimbene, The dynamics of the mentor-protege relationship in developing women as academic leaders. Journal of Educational Equity and Leadership, 1981. 2: p. 51-64.

18. Blackburn, R.T., D.W. Chapman, and S.M. Cameron, 'Cloning' in academe: mentorship and academic careers. Research in Higher Education, 1981. 15(4): p. 315-327.

19. Bolton, E.B., A conceptual analysis of the mentor relationship in the career development of women. Adult Education, 1980. 30: p. 195-207.

20. Darling, L.A.W., 'Mentors' and 'Mentoring'. The Journal of Nursing Administration, 1985. 15: p. 42-43.

21. Higgins, M.C., The more, the merrier? Multiple developmental relationships and work satisfaction. Journal of Management Development, 2000. 19(3/4): p. 277-296.

22. Hill, S.E.K., M.H. Bahniuk, and J. Dobos, The impact of mentoring and collegial support on faculty success: an analysis of support behavior, information adequacy, and communication apprehension. Communication Education, 1989. 38: p. 15-33.

23. Nielson, T.R., D.S. Carlson, and M.J. Lankau, The supportive mentor as a means of reducing work-family conflict. Journal of Vocational Behavior, 2001. 59: p. 364-381.

24. Young, A.M. and P.L. Perrewé, What did you expect An examination of career-related support and social support among mentors and protégés. Journal of Management, 2000. 26(4): p. 611-632.

25. de Janasz, S.C. and S.E. Sullivan, Multiple mentoring in academe: developing the professorial network. Journal of Vocational Behavior, 2004. 64: p. 263-283.

26. Boice, R., The new faculty member: support and fostering professional development. 1992, San Francisco: Jossey-Bass. xvii, $376 \mathrm{p}$.

27. Blackwell, J.E., Mentoring: An action strategy for increasing minority faculty. Academe, 1989. 75: p. 8-14.

28. Tierney, W.G. and E.M. Bensimon, Promotion and tenure: community and socialization in academe. 1996, Albany: State University of New York Press. x, $161 \mathrm{p}$.

29. Granovetter, M.S., The strength of weak ties. American Journal of Sociology, 1973. 78(6): p. 1360-1380.

JOYCE W. YEN - Joyce W. Yen received her Ph.D. in Industrial and Operations Engineering from the University of Michigan, Ann Arbor. She was a former assistant professor of Industrial Engineering at the University of Washington and now serves as the Program/Research Manager for the University of Washington's NSF-funded ADVANCE Center for Institutional Change.

KATE QUINN - Kate Quinn is a Ph.D. student in the Graduate Program in Higher Education at the University of Washington. She received her M.Ed. in Higher Education Leadership and Policy Studies from the UW. She is a graduate Research Assistant for UW ADVANCE CIC, developing individualized work-family policy synopses for department chairs for a national chairs workshop to take place summer 2005.

SHEILA EDWARDS LANGE - Sheila Edwards Lange is a doctoral candidate in the Educational Leadership and Policy Studies at the University of Washington. She is the Associate Director of Research in the Center for Workforce Development, and is part of the internal evaluation team for the UW ADVANCE program.

EVE A. RISKIN - Eve Riskin is Professor of Electrical Engineering and Director of the ADVANCE Center for Institutional Change at the University of Washington. Her research interests include image compression and image processing. She was awarded the NSF National Young Investigator Award in 1992 and the Sloan Research Fellowship in 1994.

DENICE D. DENTON - Denice D. Denton is Dean of the UW College of Engineering. She has won numerous awards including a 2003 Presidential Award for Excellence in Science, Mathematics and Engineering Mentoring. Beginning in February 2005, she will be Chancellor of the University of California, Santa Cruz. 